\title{
Cross-validation and integration with ground based geophysical data
}

\author{
A. Laake, C. Strobbia, A. Cutts*, L. Velasco, M. Sheneshen, WesternGeco Cairo
}

Reservoir mapping in the Gulf of Suez petroleum system is challenging because rifting fragmented the reservoirs by rift-parallel and transfer faults leaving the reservoirs confined to stratigraphic, structural, and combined traps. We have developed a technique to address this challenge that integrates fault outcrop mapping using satellite image interpretation, seismic near-surface characterization techniques such as Rayleigh wave velocity mapping and ray parameter interferometry, as well as ant tracking of faults and geobody delineation on a prestack time-migrated (PSTM) cube. The technique utilizes a combination of geographic information system (GIS) and geological modelling software for surface/subsurface integration. The joint analysis of Rayleigh wave data with satellite imagery provides a nearsurface structural geological model.

The suite of near-surface geological products is enabled by the acquisition, processing, and interpretation of point-receiver seismic data. Detailed shallow structural geology could be imaged in the near surface, a data regime that is conventionally masked by the acquisition noise from the seismic acquisition.

The shallow geological model comprises shallow lithological horizons as well as fault zones, the mapping of which may assist the mitigation of shallow drilling risks.

The integration of surface and subsurface structural mapping provides the tectonic framework for delineation of the reservoirs in the rift-faulted environment of the Gulf of Suez. 